\title{
Fixed Drug Eruption due to Achiote Dye
}

\author{
Ian Tattersall Bobby Y. Reddy \\ Department of Dermatology, Columbia University, New York, N.Y., USA
}

\section{Key Words}

Fixed drug eruption $\cdot$ Achiote $\cdot$ Tartrazine $\cdot$ Food coloring $\cdot$ Food dye

\begin{abstract}
Fixed drug eruption (FDE) is a localized type IV sensitivity reaction to a systemically introduced allergen. It usually occurs as a result of new medication, making identification and avoidance of the trigger medication straightforward; however, in a rare subset of cases no pharmacological source is identified. In such cases, the causative agent is often a food or food additive. In this report we describe a case of a FDE in a 12-year-old girl recently immigrated to the United States from Ecuador who had no medication exposure over the course of her illness. Through an exhaustive patient history and literature review, we were able to hypothesize that her presentation was caused by a dietary change of the natural achiote dye used in the preparation of yellow rice to a locally available commercial dye mix containing tartrazine, or Yellow 5, which has previously been implicated in both systemic hypersensitivity reactions and specifically in FDE. This report adds to the small body of available literature on non-pharmacological fixed hypersensitivity eruptions and illustrates an effective approach to the management of such a presentation when history is not immediately revealing.
\end{abstract}

\section{Introduction}

Fixed drug eruption (FDE) is a localized type IV sensitivity reaction to a systemically introduced allergen. It is an uncommon form of drug hypersensitivity [1] and classically manifests as a well-demarcated, pruritic patch or plaque, often with a dusky center, that occurs at the same location after every exposure. Most commonly, this eruption occurs in the context of a new medication, and the inciting agent is relatively easy to discover. However, the etiology may sometimes be elusive, as there are many published reports of FDEs due to non-

\section{KARGER}


Tattersall and Reddy: Fixed Drug Eruption due to Achiote Dye

medications, such as food coloring dyes and home remedies. We herein report the first case to our knowledge of a FDE due to achiote dye.

\section{Case Report}

A 12-year-old girl who had recently immigrated to New York City from Ecuador presented with an 8-month history of a recurring, intensely pruritic rash on her left thigh. She and her family reported that the rash had first developed within a week of their arrival in the United States and that it had appeared three times over the course of the last 8 months, with the most recent occurrence lasting for the 3 months prior to presentation. The rash always appeared the same and occurred in the same place. Neither the patient nor the family were aware of any obvious inciting factors. Both patient and family denied any use of medications, supplements or vitamins in the previous year. Review of systems was negative for accompanying fevers, chills, night sweats or weight loss.

On physical examination, there was a 6-cm well-circumscribed annular plaque with a dusky center, a central collapsed bulla and an erythematous border on her left lateral thigh a $6 \mathrm{~cm}$ (fig. 1). A 3-mm punch biopsy was performed at the periphery of the lesion. Histopathology demonstrated numerous keratinocyte necroses along with a lymphocytic perivascular infiltrate (fig. 2), consistent with the clinical diagnosis of a FDE.

The patient was instructed to apply alclometasone $0.05 \%$ cream to the lesion twice a day for 1 week. Given the lack of an obvious causative agent, the family was recommended to thoroughly review new dietary changes since emigration, particularly ingredients in processed foods and foods containing artificial coloring. At the follow-up visit 1 week later, the plaque was no longer pruritic and appeared xerotic with pink re-epithelialization at the site of the former bulla, suggesting that the lesion was beginning to resolve. After a diligent exploration, the family reported one significant dietary alteration since arriving in the United States: whereas they had previously made yellow rice using natural achiote, or annatto dye, they had switched to a commercially available achiote dye and spice mixture. On review of the ingredient label of this product, the mixture was found to contain the synthetic coloring agent Yellow 5 (tartrazine). The patient was advised to discontinue use of this product. She reported no recurrence at 4-month follow-up.

\section{Discussion}

FDEs represent a minority of hypersensitivity responses, accounting for approximately $5 \%$ of all such reactions [1]. The prevalence is higher in pediatric patients, where they account for $14-22 \%$ of drug hypersensitivity reactions $[2,3]$. The list of known causative agents is broad and similar to that of the more common morbilliform drug eruptions, including antibiotics, barbiturates, acetaminophen, allopurinol and antimalarial medications [4]. FDEs present as single or multiple, well-circumscribed round or oval patches or plaques, often with dusky centers and occasionally with vesicle or bulla formation. After an initial sensitization, onset of symptoms usually begins between $30 \mathrm{~min}$ and $8 \mathrm{~h}$ after repeat exposure and can last 7-10 days after withdrawal of the offending agent [5]. Perhaps the most defining aspect of a FDE is that it occurs in the same place with every re-exposure to the allergen; indeed, a FDE represents a heterotypic allergic hypersensitivity that is only exhibited by the local immune environment of this specific location. As a result, any attempt to determine the causative agent via patch testing must occur on the affected area only, or re- 
Tattersall and Reddy: Fixed Drug Eruption due to Achiote Dye

sults will be impossible to interpret. Systemic challenge can also be employed; however, this should be done cautiously, as FDEs can rarely recur in a more dangerous generalized bullous form.

FDEs are almost always associated with new medication. However, a small body of literature describes FDE with confirmed non-medication sources [6-14]. These sources are either food or chemical additives found in food, leading to the proposition of the term 'fixed food eruption' to describe this subset of localized hypersensitivity reaction [7]. Table 1 summarizes the 15 available case reports detailing fixed eruptions with verified food allergens. Many of these allergens are frequently seen as causes of more widely known type I hypersensitivity reactions, such as nuts, legumes and shellfish. Of note, there are many reports of quinine and quinoline yellow food dyes; these entities contain inoline cores that bear a marked structural resemblance to the fluoroquinolone antibiotics. A general, noteworthy observation is that of the allergens that were specifically identified, many were not the food itself, but rather synthetic food dyes used in its preparation.

With any case of a drug eruption with a likely food source, it is extremely difficult to determine the causative agent, and at present the source of our patient's reaction has not been definitively identified (no patch test performed). However, the patient began eating rice cooked with a commercial dye containing tartrazine (Yellow 5) when she arrived in the United States, shortly before the first occurrence of the eruption. There is one case in the literature of a drug eruption conclusively linked to tartrazine [8], and another in whom cheese crisps - a food product that frequently contains tartrazine - were implicated [6]. Thus we empirically suggested that our patient discontinue use of this dye mix and attempt to avoid future exposure to tartrazine-containing foods. This is certainly challenging, as the chemical is widely used in the production of not only foods, but also medications, leading to the possibility that future tartrazine hypersensitivity reactions may be mistaken for medication allergies. In addition, there is a known association between tartrazine allergy and aspirin allergy [15], and so it is prudent for the patient to exercise caution in the future if the use of aspirin is medically indicated.

This case illustrates the challenge inherent in the identification of rare hypersensitivity reactions occurring without a clear pharmacological source. The workup of such a case should include a thorough history with particular attention to new foods, keeping in mind that such reactions can be due to chemical dyes and additives rather than the food itself. Initial treatment is topical steroids as well as empiric avoidance of suspect foods, with the possibility of confirming the cause via subsequent patch testing or systemic challenge. This is a rare and potentially frustrating condition, and an understanding of the potential causative agents is essential for expedient and minimally disruptive management.

\section{Statement of Ethics}

The authors have no ethical conflicts to disclose. The patient provided written informed consent.

\section{Disclosure Statement}

The authors have no conflict of interest to declare. 


\section{Case Reports in Dermatology}

\begin{tabular}{l|l}
\hline Case Rep Dermatol 2016;8:14-18 \\
\hline DOI: $10.1159 / 000443949$ & $\begin{array}{l}\text { C 2016 The Author(s). Published by S. Karger AG, Basel } \\
\text { www.karger.com/cde }\end{array}$ \\
\hline
\end{tabular}

Tattersall and Reddy: Fixed Drug Eruption due to Achiote Dye

\section{References}

1 Lee AY: Fixed drug eruptions. Incidence, recognition, and avoidance. Am J Clin Dermatol 2000;1:277-285.

-2 Khaled A, Kharfi M, Ben Hamida M, El Fekih N, El Aidli S, Zeglaoui F, Ezzine N, Fazaa B, Kamoun MR: Cutaneous adverse drug reactions in children. A series of 90 cases. Tunis Med 2012;90:45-50.

-3 Sharma VK, Dhar S: Clinical pattern of cutaneous drug eruption among children and adolescents in north India. Pediatr Dermatol 1995;12:178-183.

4 Mahboob A, Haroon TS: Drugs causing fixed eruptions: a study of 450 cases. Int J Dermatol 1998;37:833838.

5 Brahimi N, Routier E, Raison-Peyron N, Tronquoy AF, Pouget-Jasson C, Amarger S, Machet L, Amsler E, Claeys A, Sassolas B, Leroy D, Grange A, Dupuy A, Cordel N, Bonnetblanc JM, Milpied B, Doutre MS,

Guinnepain MT, Barbaud A, Chosidow O, Roujeau JC, Lebrun-Vignes B, Descamps V: A three-year-analysis of fixed drug eruptions in hospital settings in France. Eur J Dermatol 2010;20:461-464.

-6 Hatzis J, Noutsis K, Hatzidakis E, Bassioukas K, Perissios A: Fixed drug eruption in a mother and her son. Cutis 1992;50:50-52.

7 Kelso JM: Fixed food eruption. J Am Acad Dermatol 1996;35:638-639.

8 Orchard DC, Varigos GA: Fixed drug eruption to tartrazine. Australas J Dermatol 1997;38:212-214.

-9 Fukushima S, Kidou M, Ihn H: Fixed food eruption caused by cashew nut. Allergol Int 2008;57:285-287.

10 Tsuruta D, Sowa J, Kobayashi H, Ishii M: Fixed food eruption caused by Japanese sand lance. Clin Exp Dermatol 2009;34:e309-e310.

11 Waton J, Splingard B, Barbaud A: A new entity: the neutrophilic fixed food eruption. Contact Dermatitis 2011;65:44-47.

12 Ramien ML, Pratt MD: Fixed drug eruption to ingested propolis. Dermatitis 2012;23:173-175.

13 Gaus BM, Scheiba N, Schakel K: Asparagus-induced fixed food eruptions mimicking cutaneous lupus. Acta Derm Venereol 2014;94:731-732.

14 Parker AL, Pinson ML, Wohltmann WE, Gomez R: Fixed food eruption caused by peanut and cashew: a case report and review of the literature. J Allergy Clin Immunol Pract 2015;3:119-122.

15 Grzelewska-Rzymowska I, Szmidt M, Kowalski ML, Rozniecki J: Sensitivity and tolerance to tartrazine in aspirin-sensitive asthmatics. Allergol Immunopathol (Madr) 1986;14:31-36.

Table 1. Documented cases of fixed hypersensitivity eruptions with non-pharmacological sources, including both foods and food additives

\begin{tabular}{lll}
\hline Allergen & $\begin{array}{l}\text { Number } \\
\text { of cases }\end{array}$ & References \\
\hline Cashew & 3 & 9,14 \\
Peanut & 1 & 14 \\
Lentil & 2 & 9 \\
Bee pollen (propolis) & 1 & 12 \\
Strawberry & 1 & 7 \\
Asparagus & 2 & 9,13 \\
Lactose & 1 & 9 \\
Tonic water (quinine) & 4 & 9 \\
Quinoline yellow dye $_{\text {Cheese crisps (+/- tartrazine) }}{ }^{1}$ & 1 & 9 \\
Seafood & 2 & 6,8 \\
\hline
\end{tabular}

This table represents an updated version of a previously compiled 2008 list [9].

${ }^{1}$ The specific causative agent (the dye tartrazine/Yellow 5) was identified in one of the two reports. 


\section{Case Reports in Dermatology}

\begin{tabular}{l|l}
\hline Case Rep Dermatol 2016;8:14-18 \\
\hline DOI: $10.1159 / 000443949$ & $\begin{array}{l}\text { (c) 2016 The Author(s). Published by S. Karger AG, Basel } \\
\text { www.karger.com/cde }\end{array}$ \\
\hline
\end{tabular}

Tattersall and Reddy: Fixed Drug Eruption due to Achiote Dye

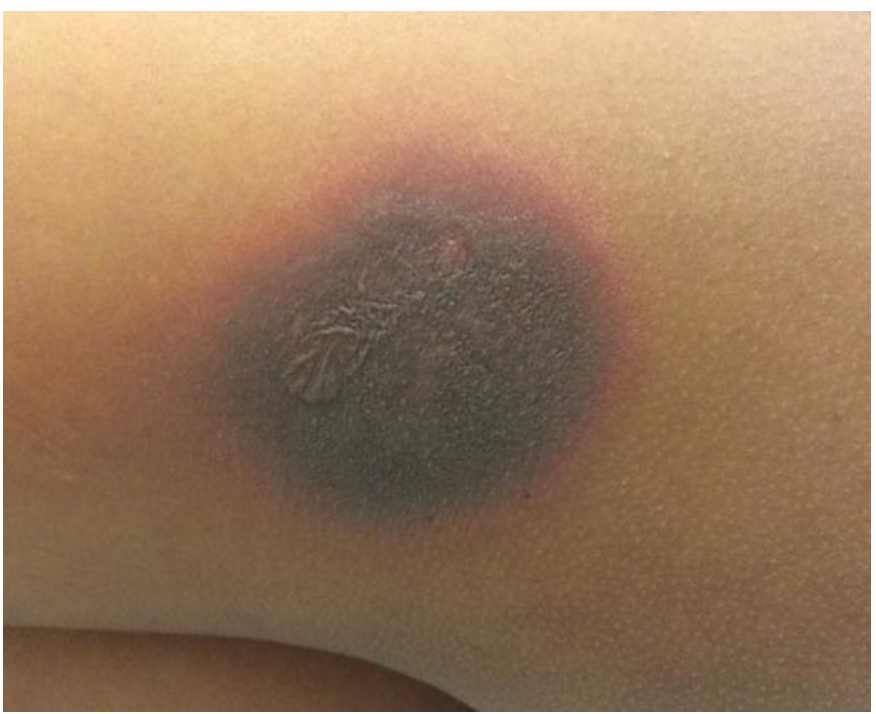

Fig. 1. Clinical presentation: a 6-cm, well-demarcated plaque with a dusky center, erythematous border and central collapsed bulla.

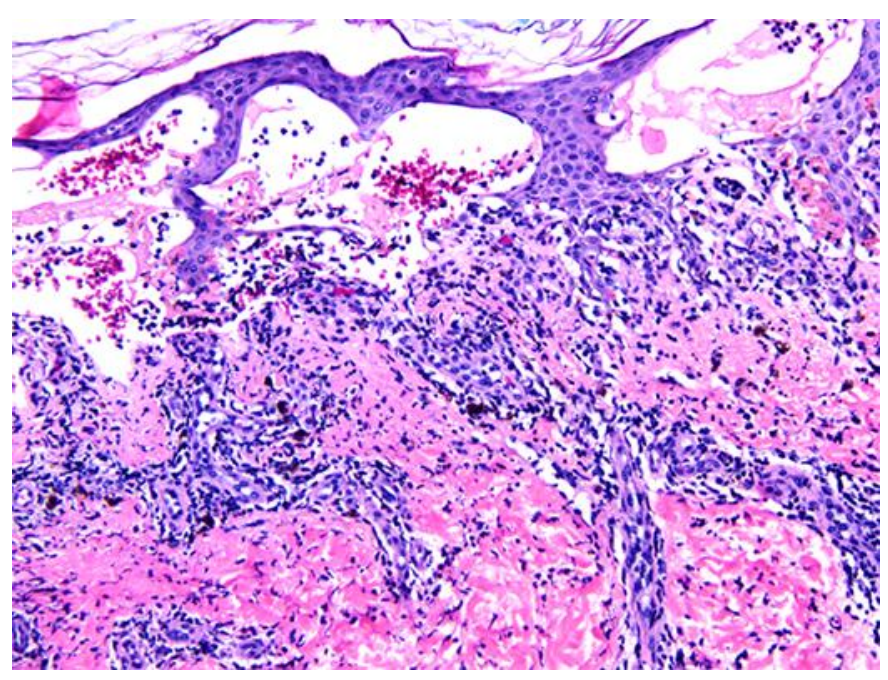

Fig. 2. Histological examination: keratinocyte necrosis and diffuse lymphocytic inflammatory infiltrate. 